\title{
Cost of delay and endogenous price leadership
}

\author{
Ivan Pastine ${ }^{\mathrm{a}, *}$, Tuvana Pastine ${ }^{\mathrm{b}, *}$ \\ ${ }^{a}$ Economics Department, University College Dublin and CEPR, Dublin 4, Ireland \\ ${ }^{\mathrm{b}}$ Department of Economics, NUI Maynooth and CEPR, Maynooth, County Kildare, Ireland
}

Received 27 June 2000; received in revised form 28 September 2001; accepted 26 May 2003

\begin{abstract}
We study the effects of discounting in a standard endogenous price leadership model. We show that there will be occasional changes in the identity of the leader with any cost of delay or discounting, however small. By analyzing the incentives that induce a firm to take up the leader position, we derive positive predictions about which firm will lead most price changes. Firms with shorter reaction times will be more likely to become the price leader, as will firms with lower cost of delay if the firms' reaction times are similar.
\end{abstract}

(C) 2003 Elsevier B.V. All rights reserved.

JEL classification: L10

Keywords: Endogenous timing; Price leadership; War of attrition

\section{Introduction}

Case studies find that in a wide variety of oligopolistic industries, such as the cigarette, steel, automobile, ready-to-eat-cereal and gasoline industries, new price announcements arrive in a sequential manner: price increases by one firm are followed immediately by its rivals. Compared with simultaneous price competition, this leader-follower time pattern of pricing typically yields higher prices for both the leader and the follower firm. Hence, it is difficult for regulatory authorities to distinguish collusive price leadership from a leader-follower pattern that emerges as a noncooperative equilibrium outcome.

This paper inquires into the types of outcomes that are likely to arise as the result of noncooperative competition between similar, symmetrically informed firms. ${ }^{1}$ First, we

* Corresponding authors.

E-mail addresses: Ivan.Pastine@ucd.ie (I. Pastine), Tuvana.Pastine@may.ie (T. Pastine).

1 Rotemberg and Saloner (1990) and Eckard (1982) analyze the role of informational asymmetries in endogenous price leadership. 
show that in such industries, there will be occasional changes in the identity of the price leader. A leader-follower pattern where a single firm consistently leads all price changes is unlikely if firms face a cost of delay in their price announcements. Secondly, by analyzing the incentives that induce a firm to take up the leader position, we derive positive predictions about which firm will lead most price changes.

In many industries, empirical studies by Scherer and Ross (1990), Nicholls (1951) and Markham (1951) show that the identity of the leader tends to vary. One of the "distinguishing characteristics" of price leadership in industries that do not have a dominant firm is occasional changes in the identity of the leader firm (Scherer and Ross, 1990, p. 249). For instance, in the US cigarette industry from 1923 to 1941, there were eight standard brand price changes. While Reynolds lead six of these price changes, American led the other two price changes. In the 1960s steel industry, price leadership passed from one company to another with price changes being announced in different product lines. Markham (1951) reports that in the newsprint industry, while International Paper led most price changes in markets east of the Rocky Mountains, it did not lead all of the price changes. Likewise, Crown Zellerbach has usually announced new prices on the West Coast, but its rivals lead some price changes as well.

There is a line of research which derives predictions about which firm will become the price leader. Among these, Van Damme and Hurkens (1998) show that an equilibrium refinement (risk dominance) will pick the low-cost firm as the price leader no matter how similar the firms might be, as long as they are not identical. In Deneckere and Kovenock (1992) and Deneckere et al. (1992), differences in capacity constraints and brand loyalty can generate an endogenous price leader as a result of a pure-strategy equilibrium. The findings of our paper, on the other hand, predict occasional changes in the identity of the leader. The reasons for the difference in these predictions are twofold: we explicitly incorporate a cost of delay in price announcements and we allow the firms to act whenever they wish.

When firms are restricted in the timing of their moves, such that in odd periods one firm can announce price and in even periods the other firm can announce price, Deneckere and Kovenock (1992) and Deneckere et al. (1992) show that the high capacity firm and/or the firm with a greater brand-loyal group of consumers will emerge as the endogenous price leader. However, as also noted in Deneckere and Kovenock (1992), relaxing the restriction on the timing of the moves such that each firm can move in any period, endogenous price leadership as a pure-strategy equilibrium outcome disappears when firms discount the future. Our framework extends the endogenous leadership discussion by examining the nature of the competition under these circumstances.

We argue that a cost of delay in price announcement may play an important role in firms' strategic pricing decisions. A firm can collect sales receipts at the new prices only after having announced its price. Hence, a delay in the price announcement will inevitably result in delayed and, therefore, discounted profits for the firm. When firms incur any cost of delay in price announcements, however small, a leader-follower pattern cannot emerge as a result of a pure-strategy Nash equilibrium.

Hence, we examine the mixed-strategy equilibria. In price competition, the mixedstrategy equilibrium is a war of attrition. Due to the basic conflict over role selection, firms struggle to capture the advantageous follower position. In the war of attrition, 
asymmetries between the firms translate into asymmetric probabilities of leading. Therefore, while one firm might lead many price changes, the same firm will not lead all price changes.

\section{A standard model of endogenous price leadership}

Consider a duopolistic market with differentiated products where risk-neutral, profitmaximizing firms, A and B compete in prices. ${ }^{2}$ There are two periods, and each firm must make a price commitment either in period one or in period two. ${ }^{3}$ In period one, firms simultaneously decide whether or not to commit and if so, what price to commit to, not observing each other's decision. If the firm waits and its rival commits, the firm can observe rival's commitment price while setting its price in the second period. If both firms wait, they set their prices simultaneously in period two. Consumers make their purchasing decisions as soon as both firms announce their prices. This framework corresponds to the extended game with action commitment model of Hamilton and Slutsky (1990) which has been widely used to study endogenous price leadership. ${ }^{4}$

Each firm has a twice differentiable, strictly concave profit function which is increasing in the rival's price. Given firm $j$ 's price $p_{j}$, firm $i$ 's optimal price solves the first-order condition $\partial \Pi_{i}\left(p_{i}, p_{j}\right) / \partial p_{i}=0$, where $i, j \in\{\mathrm{A}, \mathrm{B}\}, i \neq j$. These equations implicitly define reaction functions, $p_{i}=R_{i}\left(p_{j}\right)$ which are assumed to be upward-sloping. ${ }^{5}$ It is also assumed that there exists a unique and stable set of "simultaneous" prices where the reaction functions cross, $p_{i}^{\mathrm{S}}=R_{i}\left(p_{j}^{\mathrm{S}}\right){ }^{6}$ The profit functions evaluated at these simultaneous prices are denoted by $\Pi_{i}^{\mathrm{S}}, i \in\{\mathrm{A}, \mathrm{B}\}$. The profit of firm $i$ when it is the leader is given by $\Pi_{i}\left(p_{i}, R_{j}\left(p_{i}\right)\right)$, which is assumed to be strictly concave. The optimal "leadership" price is denoted by $p_{i}^{\mathrm{L}}$. The reaction function of the follower firm $j$, evaluated at $p_{i}^{\mathrm{L}}$ yields firm $j$ 's optimal "follower" price, $p_{j}^{\mathrm{F}}=R_{j}\left(p_{i}^{\mathrm{L}}\right)$. The optimized leadership profit $\Pi_{i}\left(p_{i}^{\mathrm{L}}, p_{j}^{\mathrm{F}}\right)$ is denoted by $\Pi_{i}^{\mathrm{L}} \cdot 7$ The optimized follower profit $\Pi_{j}\left(p_{i}^{\mathrm{L}}, p_{j}^{\mathrm{F}}\right)$ is denoted by $\Pi_{j}^{\mathrm{F}}$.

\footnotetext{
2 Holthausen (1979) stresses the importance of the degree of risk aversion in endogenous price leadership models.

3 In this paper, we will follow much of the endogenous leadership literature in assuming that firms are able to credibly commit to their prices. Once a firm announces its price, it cannot change it. While this is a common assumption in the literature, it does imply that the framework is far from a complete characterization of the firms' strategic problem. More work needs to be done to understand how firms may address the commitment problem. Not only is this an important issue in its own right, but the way in which firms attempt to commit may also affect the nature of the competition between them and, hence, their struggle over leader and follower roles. Work by Henkel (1999) shows one method of endogenizing the commitment level.

4 See Hamilton and Slutsky (1990) for a formal definition of the game. See also Amir (1995).

5 Upward-sloping reaction functions, which are typically assumed in price competition, require that the cross partial derivatives of the profit functions are positive.

6 Stability implies that at the simultaneous prices $\left(\partial R_{\mathrm{B}} / \partial p_{\mathrm{A}}\right)<1 /\left(\partial R_{\mathrm{A}} / \partial p_{\mathrm{B}}\right)$.

7 When the leadership first-order condition, $\left(\partial \Pi_{i} / \partial p_{i}\right)+\left(\partial \Pi_{i} / \partial p_{j}\right)\left(\partial R_{j} / \partial p_{i}\right)=0$, is evaluated at the simultaneous price, the left-hand side is positive since the profit function is increasing in the rival's price, and the reaction function is positively sloped. Therefore, $p_{i}^{\mathrm{L}}>p_{i}^{\mathrm{S}}$. While the leader firm has the option of quoting its simultaneous price and receiving its simultaneous profit, it will not choose to do so, hence, $\Pi_{i}^{\mathrm{L}}>\Pi_{i}^{\mathrm{S}}$.
} 
For the purpose of this paper, we will define a leader-follower outcome to be any outcome that may possibly help to explain the empirically observed phenomenon of price leadership. That is any outcome where one firm announces its price first and the other announces its price an observable (nonzero) amount of time after the leader. A leaderfollower equilibrium will be any equilibrium which yields a nonzero probability of a leader-follower outcome. In the context of this two-period discrete-time model, a leaderfollower outcome would involve one firm moving in period one and the other moving in period two.

Hamilton and Slutsky (1990, Theorem VII) show that in this framework, multiple subgame-perfect, pure-strategy leader-follower Nash equilibria exist including each firm waiting and the other playing its Stackelberg leader price in the first period.

In Hamilton and Slutsky (1990), firms do not discount the future, and they do not face a cost of delay in their price announcements. However, costs of delay arise naturally in price announcement games. Firms will not receive the benefit of new prices until they announce their price, in which case discounting will introduce a cost of delay. Additionally, firms may incur costs due to foregone sales in the face of late price quotations. When consumers are unable to preplan due to lack of information about price, demand may decrease.

In fact, pure-strategy, leader-follower equilibria disappear if firms incur any cost of delay in price announcements, however small the cost might be. ${ }^{8}$ When $i$ expects $j$ to commit to $p_{j}$ in period one, it is in $i$ 's best interest to quote $R_{i}\left(p_{j}\right)$. With any cost of delay, however small, $i$ strictly prefers to quote $R_{i}\left(p_{j}\right)$ in period one rather than in period two, since it can capture the same profit in the first period and avoid the cost of delay. Hence, $j$ leading and $i$ following is not an equilibrium when firms face a cost of delay, however small the cost of delay. This result suggests that the conclusions of the pure-strategy leader-follower equilibria are unlikely to be a convincing explanation for most observed price leadership.

Nevertheless, empirical observations suggest that price leadership is quite common. One reasonable interpretation could be that firms are playing a mixed-strategy equilibrium, randomizing between committing early and waiting to announce price. ${ }^{9}$ In this context, it would be intuitively appealing. Dowrick (1986) shows that both firms will typically prefer to be the follower to being the leader in price competition when firms have upward-sloping reaction functions. ${ }^{10}$ Dowrick notes that it may also be possible for firms with sufficiently dissimilar profit functions to agree on the choice of roles. We will concentrate on the cases where firms are not too dissimilar, so there is an element of conflict in role selection. We restrict attention to the set of profit function pairs which yield leadership prices above the follower prices, $p_{i}^{\mathrm{L}}>p_{i}^{\mathrm{F}}$. Since, by definition, a firm's follower price is its best response to

\footnotetext{
8 See Deneckere and Kovenock (1992, footnote 12). In Robson (1990), sales take place at the deadline, no matter how early the firms might announce their prices. Since there is no cost of delay in price announcements in his framework, Robson finds that there are multiple pure-strategy leader-follower equilibria.

9 The literature has noted the possibility of such an equilibrium (see Hamilton and Slutsky, 1990; Robson, 1990; Deneckere and Kovenock, 1992).

${ }^{10}$ In addition, see Gal-Or (1985). Amir and Grilo (1999), Boyer and Moreaux (1987) and Ono (1982) discuss closely related questions.
} 
its rival's leader price, it follows that $\Pi_{i}\left(p_{i}^{\mathrm{F}}, p_{j}^{\mathrm{L}}\right) \geq \Pi_{i}\left(p_{i}^{\mathrm{L}}, p_{j}^{\mathrm{L}}\right)$. And since the profit function is increasing in the rival's price, $\Pi_{i}\left(p_{i}^{\mathrm{L}}, p_{j}^{\mathrm{L}}\right)>\Pi_{i}\left(p_{i}^{\mathrm{L}}, p_{j}^{\mathrm{F}}\right)$. Therefore, both firms will want to capture the follower position. In this case, a mixed-strategy equilibrium could be interpreted as the "chicken" variation of the war of attrition. ${ }^{11}$

However, below we show that in this framework a nondegenerate, mixed-strategy equilibrium does not exist. Thus, with a cost of delay, there is no equilibrium which yields any chance of a leader-follower outcome.

Proposition 1: With a cost of delay, the unique subgame-perfect equilibrium involves immediate and simultaneous moves in the first period.

See proof in Appendix A.

\section{Relaxing the restrictions on the timing of firms' moves}

The framework presented in the previous section of the paper permits direct comparison of the results with the existing literature on endogenous leadership. The introduction of a cost of delay in price announcements, however small, is shown to change the predictions of the model: a leader-follower outcome cannot occur as the result of a noncooperative equilibrium. However, under this specification the framework no longer has explanatory power for observed price leadership. Since a cost of delay in price announcement games is quite a realistic assumption, how can we reconcile theory and empirical observation?

A number of restrictions on the timing of firms' moves are embedded in the twoperiod, discrete-time framework. A firm that delays must wait an entire period before it announces its price and the firms are not permitted to delay past period two. In this section, we relax these assumptions and allow the firms to announce their prices whenever they wish. We show that when these restrictions are relaxed, the theory does generate endogenous leadership and we can make positive predictions about the identity of the leader firm.

Thus, we look at an infinite-horizon, continuous-time version of the model. As before, the game ends as soon as both firms make their price announcements, and each firm receives profits which depend on prices as specified in Section 2. In this price announcement game, the continuous-time formulation has two advantages. First, the continuous-time framework allows the firms to act whenever they wish, avoiding arbitrary restrictions on the timing of their actions. Secondly, the equilibrium that yields interesting predictions in the framework without a deadline will prove to be in mixed strategies and, hence, the continuous-time formulation is technically convenient. However, in continuous time when firms can respond instantaneously, leader-follower outcomes are observationally indistinguishable from simultaneous price announcements. In reality, firms are

11 In the classic game of chicken, two cars drive toward a cliff and the first driver to turn away loses (captures the leader profit) while his rival wins (captures the follower profit). However, if neither driver turns away, they drive over the cliff (engage in simultaneous price competition). 
observed to respond with a short but perceptible lag, which is what yields the empirical evidence of price leadership. To match this reality, we will assume that it takes a fixed time to react to the rival's actions. In the previous section, the assumption of a minimum response time was already embedded in the discrete-time setting. ${ }^{12}$ Hence, in this section, we will keep the reaction lag spirit of the discrete-time framework, but allow the firms to act whenever they wish by moving to continuous time.

The actions of the rival are immediately observable but it takes firm $i$ a fixed length of time $m_{i}>0$ to react to the actions of its rival. That is, if firm $i$ wishes to adopt a strategy that conditions its price announcement on its rival's price, then the firm's announcement must occur at least $m_{i}$ after its rival's announcement. The firm still has the option of announcing its price earlier, but if it does so then its price cannot be conditional on its rival's price. Sales take place only after both firms have announced their prices. We incorporate a cost of delay in price announcements via discounting. Firms discount the future at the rate $r_{i} \in(0, \infty), i \in\{\mathrm{A}, \mathrm{B}\}$. Since $p_{i}^{\mathrm{F}}$ is the optimal reaction to $p_{j}^{\mathrm{L}}$, it is always true that $\Pi_{i}\left(p_{i}^{\mathrm{L}}, p_{j}^{\mathrm{L}}\right)<\Pi_{i}\left(p_{i}^{\mathrm{F}}, p_{j}^{\mathrm{L}}\right)$. We will assume that firms' reaction time is short enough that it does not change this basic incentive of the firms to capture the follower position: $\Pi_{i}\left(p_{i}^{\mathrm{L}}, p_{j}^{\mathrm{L}}\right)<e^{-m_{i} r_{i}} \Pi_{i}\left(p_{i}^{\mathrm{F}}, p_{j}^{\mathrm{L}}\right)$.

Attention is restricted to subgame-perfect equilibria. Simultaneous announcement of $p_{A}^{S}$ and $p_{\mathrm{B}}^{\mathrm{S}}$ is an equilibrium outcome in this model for the same reason as it was in the twoperiod discrete-time model. Of interest here is what types of leader-follower outcomes are possible.

Proposition 2: Subgame-perfect leader-follower equilibria can only arise due to a mixedstrategy equilibrium where firms randomize over their price-announcement times. There exists such an equilibrium where the price announcement time for firm $j$, conditional on no price announcement by firm $i$, has an exponential distribution with p.d.f. $q_{j} e^{-q_{j} t}$, for $t \geq 0$, where $q_{j}=\left\{\left(r_{i} \Pi_{i}^{L}\right) /\left(\Pi_{i}^{F} e^{\left(m_{j}-m_{i}\right) r_{i}}-\Pi_{i}^{L}\right)\right\}$ is the hazard rate, $i, j \in\{A, B\}, i \neq j$.

Proof: Define $z_{i}$ and $z_{j}$ as the deterministic price-announcement times that result from pure strategies $s_{i}$ and $s_{j}$. Without loss of generality, assume that $z_{i} \leq z_{j}$. If $z_{j}>z_{i}+\varepsilon$, then $s_{j}$ cannot be optimal given $s_{\mathrm{i}}$ since firm $j$ would strictly prefer to make its price announcement at $z_{i}$, avoiding the cost of delay. If $z_{j}$ is in the open interval around $z_{i}$, then $z_{j}<z_{i}+m_{j}$ so $j$ 's price cannot be conditional on $i$ 's price. Thus, both firms must be on their reaction functions yielding price announcements of $p_{i}^{\mathrm{S}}=R_{i}\left(p_{j}^{\mathrm{S}}\right)$ and $p_{j}^{\mathrm{S}}=R_{j}\left(p_{i}^{\mathrm{S}}\right)$, an equilibrium which is observationally equivalent to simultaneous price competition. Leader-follower outcomes cannot arise as the result of pure-strategy equilibria.

The strictly concave profit functions imply that the firms will never mix in prices. Consider a possible stationary mixed-strategy equilibrium with behavior strategies for each firm $j$ of the form: "If neither firm has announced price by time $\tau$, then announce $p_{j}^{L}$ at $\tau$ with probability $q_{j}$. If $i$ announced price at time $\tau$ and $j$ did not, then announce $p_{j}=R_{j}\left(p_{i}\right)$ at time $\tau+m_{j}$." If these strategies form a mixed-strategy equilibrium, the probabilities $q_{\mathrm{A}}$ and $q_{\mathrm{B}}$ are such that each firm is indifferent between committing to its

12 See Simon and Stinchcombe (1989) for a comparison of games in discrete time versus continuous time and for a clear discussion on the "length of reaction"in these two frameworks. 
leadership price at time $\tau$ and waiting a short period of time $\mathrm{d} t$ in hopes that the rival commits. For small $\mathrm{d} t$, the probability that firm $j$ announces its price in the interval $[\tau, \tau+\mathrm{d} t]$ can be approximated by $q_{j} \mathrm{~d} t$, and this indifference becomes:

$$
\Pi_{i}^{\mathrm{L}} e^{-m_{j} r_{i}}=\left[q_{j} \mathrm{~d} t\right] \Pi_{i}^{\mathrm{F}} e^{-\left(m_{i}+\mathrm{d} t\right) r_{i}}+\left[1-q_{j} \mathrm{~d} t\right] \Pi_{i}^{\mathrm{L}} e^{-\left(m_{j}+\mathrm{d} t\right) r_{i}}
$$

The left-hand side gives $i$ 's payoff from committing. Since sales take place once both firms have announced price, the leader profit is received when the rival reacts. Hence, the profit is discounted by $e^{-m_{j} r_{i}}$. The right-hand side gives the expected payoff from waiting a short time $\mathrm{d} t$. With probability $q_{j} \mathrm{~d} t$, the rival will commit in this interval. The firm would then follow $m_{i}$ later, and receive the discounted follower profit. With a probability $\left(1-q_{j} \mathrm{~d} t\right)$, however the rival will wait, in which case the firm will get the discounted continuation value of the game. Since the equilibrium is stationary and the firm is indifferent between leading and waiting at each point in time, the continuation value is equal to $\Pi_{i}^{\mathrm{L}} e^{-m_{j} r_{i}}$. Solving Eq. (1) for $q_{j}$ and letting $\mathrm{d} t \rightarrow 0$ yields the $q_{j}$ that makes firm $i$ indifferent between committing and waiting an instant to announce price:

$$
q_{j}=\frac{r_{i} \Pi_{i}^{\mathrm{L}}}{\Pi_{i}^{\mathrm{F}} e^{\left(m_{j}-m_{i}\right) r_{i}}-\Pi_{i}^{\mathrm{L}}} \forall i, j \in\{\mathrm{A}, \mathrm{B}\} i \neq j
$$

This is positive and exists so the proposed strategies do form an equilibrium. This mixedstrategy equilibrium is subgame perfect: at any point in time where neither firm has announced price, the firms' problem is the same and they will be willing to choose the same strategies.

In markets where firms face any cost of delay, however small, leader-follower outcomes can only occur as the result of a mixed-strategy equilibrium. This mixedstrategy equilibrium takes the natural interpretation of a war of attrition. Since each firm prefers the follower position, the disagreement over roles leads to a struggle as each firm tries to gain the more profitable position. Each firm would like to wait to quote price with the hope of getting the rival to announce price early. However, each firm would consider moving early and accepting the leader profit in order to avoid the cost of delay in the event that the rival waits as well.

The probabilities in Eq. (2) have the familiar properties of mixed-strategy equilibria. As the benefit of a position to a firm increases, so does the probability that its rival captures that position. However, unlike in many mixed-strategy equilibria, here a firm's probability of moving depends on the cost and demand conditions of both firms. While $q_{j}$ is a function of its rival's profits, $\Pi_{i}^{\mathrm{L}}$ and $\Pi_{i}^{\mathrm{F}}$, these depend on both firms' leader and follower prices which are chosen strategically and, hence, depend on the cost and demand conditions facing both firms.

Notice that firms would face the same incentives if they had existing prices as long as their flow profits from these existing prices were less than the flow profits as a price leader. Suppose that $x_{i}^{j}$ is the present value of firm $i$ 's flow profits over the interval $m_{j}$ at the existing prices and redefine $\Pi_{i}^{\mathrm{L}}$ and $\Pi_{i}^{\mathrm{F}}$ as the present value of the infinite stream of profits as a leader or follower respectively. If sales at the new prices take place once both firms have 
announced their new prices, then the left hand side of Eq. (1) will go up by $\left[q_{j} \mathrm{~d} t\right] x_{i}^{j}$ while the right-hand side will go up by $\left[q_{j} \mathrm{~d} t\right] x_{i}^{i}+\left[1-q_{j} \mathrm{~d} t\right] x_{i}^{j}$. If $m$ is small for both firms, the values $x_{i}^{i}$ and $x_{i}^{j}$ are small, and the basic problem is unchanged: if both $m_{\mathrm{A}}$ and $m_{\mathrm{B}} \rightarrow 0$, the resulting equilibrium probabilities would approach those found in Proposition 2. However, if sales at a new price start taking place the moment the new price is announced, then the firms will have to take into account the fact that their choice of price will affect the profits they receive in the interval $m$, the amount of time the rival needs to react. These profits and, hence, the choice of leader price and probability of leading, will depend on the initial price of the rival. Nevertheless, if both firms' reaction times are small the relative importance of these profits while waiting for the rival to react will be small, and the basic nature of the game will be unchanged.

\section{Discussion}

In the war of attrition, equilibrium differences between the firms translate into asymmetric probabilities of announcing price (Eq. (2)). When firms have identical discount rates and reaction times, the war of attrition equilibrium implies that the firm with the relatively high follower/leader profit ratio $\left(\Pi^{\mathrm{F}} / \Pi^{\mathrm{L}}\right)$ will tend to lead more often. While this ratio appears fairly often in the endogenous leadership literature, to date there are no general results on how different factors influence it. ${ }^{13}$

Firms may have different organizational structures that yield different speed of reaction. An increase in $m_{i}$ will decrease $q_{i}$ and increase $q_{j}$. Hence, the firm with the shorter reaction time will be more likely to become the price leader. This result is interesting to compare to the results found in work on informational asymmetries and endogenous price leadership, Eckard (1982) and Rotemberg and Saloner (1990). These papers find that the firm with better access to information will tend to be the price leader. The results here are similar, but rather than the firms' access to information it is the firms' ability to react quickly to new information that influences the probability of becoming the price leader.

Differences in the firms' costs of delay will also result in differences in the probability of becoming the price leader.

$$
\frac{\partial q_{j}}{\partial r_{i}}=\frac{q_{j}}{r_{i} \Pi_{i}^{\mathrm{L}}}\left[\Pi_{i}^{\mathrm{L}}-\Pi_{i}^{\mathrm{F}} q_{j}\left(m_{j}-m_{i}\right) e^{\left(m_{j}-m_{i}\right) r_{i}}\right]
$$

The direct effect of an increase in a firm's cost of delay (the first term in the brackets of Eq. (3)) is that ceteris paribus it finds waiting to be less attractive. Hence, in equilibrium

13 The are specific examples, however. In Deneckere et al. (1992), as the firm with the larger segment of brand loyal costumers increases its costumer base, the relative follower/leader profit ratio of the firm with a smaller base goes down. In our framework as in theirs, this would imply a higher probability for the larger firm to lead. In Deneckere and Kovenock (1992), the way the follower/leader profit ratio relates to the discount factor yields different predictions on the identity of leader. However these examples are not directly comparable to our model due to their discontinuous reaction functions and restriction on the timing of moves. There is a need in the literature for further investigation of the determinants of the follower/leader profit ratio and search for more general, unifying results on it. 
the rival's probability of moving early must increase, keeping it indifferent between announcing its price and waiting. However, there is also an indirect effect (the second term in the brackets of Eq. (3)). This arises if firms have different reaction times. Moving first means that the firm will have to wait for its rival to react. If the rival moves first, the firm will have to wait during its own reaction time. An increase in a firm's cost of delay makes the differences in reaction times more important in the firms decisions. If the rival's reaction time is greater than the firm's $\left(m_{j}>m_{i}\right)$, then this effect will make moving early relatively less attractive and, hence, in equilibrium the rival's probability of moving early must decrease to compensate. One can come up with examples where the differences in the firms' reaction times are so large that as the firm's cost of delay goes down the firm is less likely to lead. Nevertheless, if the firms' reaction times are not too dissimilar, then the firm that is facing a lower cost of delay will be more likely to be the price leader. To the extent that large firms have access to lower interest rates than smaller firms, which is often found empirically, ${ }^{14}$ large firms would be more likely to lead price changes. This is the pattern which is observed in many industries. ${ }^{15}$

\section{Conclusion}

This paper analyzes the types of leader-follower outcomes that are likely to arise as the result of noncooperative competition between similar, symmetrically informed duopolistic firms. If firms have any cost of delay, however small, all pure-strategy equilibria involve simultaneous price announcements. However, when we allow firms to announce their prices whenever they like there exists an equilibrium where both firms mix over the timing of their moves and a leader-follower pattern in pricing may be observed. This mixedstrategy equilibrium is a war of attrition, since both firms struggle to capture the follower position. If this equilibrium is repeated for successive price changes, the paper predicts occasional changes in the identity of the endogenous price leader. The probabilities that each firm becomes the endogenous price leader are also derived.

As early as 1934, von Stackelberg argued that in oligopolistic markets, the conflict between the firms over the leader and follower roles will lead to an unstable market, as firms continually struggle to gain the advantageous position. "A regular trial of strength emerges and no equilibrium position is reached...[The pure-strategy "Stackelberg" leader-follower] equilibrium is unstable, for the passive seller can always take up the struggle again at any time...[E]ach duopolist tries in each case to induce his competitor to adopt another behavior pattern so that he is forced to give in." (Von Stackelberg, 1952, p. 194). Likewise, in an influential paper, Markham (1951, p. 897) argued that "there are certain visible market features associated with competitive price leadership....[I]n the absence of conspiracy one would certainly expect occasional changes in the identity of the price leader." The mixed-strategy equilibrium presented here is in line with the intuitive arguments of von Stackelberg and Markham.

\footnotetext{
14 See Gertler and Gilchrist (1994) for references to the empirical evidence. See Martinelli (1997) for a theoretical explanation.

15 See Stigler (1947) for evidence from US industries.
} 


\section{Acknowledgements}

We would like to thank Steve Dowrick, Dave Furth, Paul Klemperer, Dan Kovenock, Szilvia Papai, Margaret Slade, Gamze Tabak and two anonymous referees for helpful comments. Responsibility for errors remains our own.

\section{Appendix A}

Proof of Proposition 1: As shown in the text, when there is a cost of delay, there is no subgame-perfect, pure-strategy leader-follower equilibrium. Since the profit functions are strictly concave, firms will never mix in prices. It remains to be shown then that there does not exist an equilibrium where firms randomize over the timing of their price announcements. Suppose there existed a nondegenerate mixed-strategy equilibrium where $j$ commits before the deadline with probability $q_{j} \in(0,1)$. Concavity of the profit functions implies that the commitment price of $i$ is unique. Denote it by $p_{i}^{C}$. It solves the first-order condition:

$$
q_{j}\left[\frac{\partial \Pi_{i}\left(p_{i}, p_{j}^{C}\right)}{\partial p_{i}}\right]+\left(1-q_{j}\right) \delta_{i}\left[\frac{\partial \Pi_{i}\left(p_{i}, R_{j}\left(p_{i}\right)\right)}{\partial p_{i}}+\frac{\partial \Pi_{i}\left(p_{i}, R_{j}\left(p_{i}\right)\right)}{\partial p_{j}} \frac{\partial R_{j}}{\partial p_{i}}\right]=0
$$

$i, j \in\{\mathrm{A}, \mathrm{B}\}$ and $i \neq j$. If $p_{i}^{\mathrm{C}} \geq p_{i}^{\mathrm{L}}$, then the second bracketed term is nonpositive, since it is equal to zero at $p_{i}^{\mathrm{L}}$. Therefore, the first bracketed term must be nonnegative, implying that $p_{i}^{\mathrm{C}} \leq R_{i}\left(p_{j}^{\mathrm{C}}\right) . p_{i}^{\mathrm{F}} \equiv R_{i}\left(p_{j}^{\mathrm{L}}\right)<p_{i}^{\mathrm{L}} \leq p_{i}^{\mathrm{C}} \leq R_{i}\left(p_{j}^{\mathrm{C}}\right)$, so $p_{i}^{\mathrm{C}} \geq p_{i}^{\mathrm{L}}$ implies $p_{j}^{\mathrm{C}}>p_{j}^{\mathrm{L}}$. By the same argument, this implies $p_{j}^{\mathrm{C}}<R_{j}\left(p_{i}^{\mathrm{C}}\right)$. However, since simultaneous prices are unique and stable, both $p_{i}^{\mathrm{C}} \leq R_{i}\left(p_{j}^{\mathrm{C}}\right)$ and $p_{j}^{\mathrm{C}}<R_{j}\left(p_{i}^{\mathrm{C}}\right)$ are not possible when $p_{i}^{\mathrm{C}}>p_{i}^{\mathrm{S}}$ and $p_{j}^{\mathrm{C}}>p_{j}^{\mathrm{S}}$. Hence, $p_{i}^{\mathrm{C}}<$ $p_{i}^{\mathrm{L}}$. If $p_{i}^{\mathrm{C}} \leq p_{i}^{\mathrm{S}}$, the second bracketed term is positive since $p_{i}^{\mathrm{S}}<p_{i}^{\mathrm{L}}$. Therefore, the first bracketed term must be negative, implying $p_{i}^{\mathrm{C}}>R_{i}\left(p_{j}^{\mathrm{C}}\right), p_{i}^{\mathrm{S}} \equiv R_{i}\left(p_{j}^{\mathrm{S}}\right) \geq p_{i}^{\mathrm{C}}>R_{i}\left(p_{j}^{\mathrm{C}}\right)$, so $p_{i}^{\mathrm{C}} \leq p_{i}^{\mathrm{S}}$ implies $p_{j}^{\mathrm{C}}<p_{j}^{\mathrm{S}}$. By the same argument, this implies $p_{j}^{\mathrm{C}}>R_{j}\left(p_{i}^{\mathrm{C}}\right)$. However, since simultaneous prices are unique and stable, both $p_{i}^{\mathrm{C}}>R_{i}\left(p_{j}^{\mathrm{C}}\right)$ and $p_{j}^{\mathrm{C}}>R_{j}\left(p_{i}^{\mathrm{C}}\right)$ are not possible when $p_{i}^{\mathrm{C}} \leq p_{i}^{\mathrm{S}}$ and $p_{j}^{\mathrm{C}} \leq p_{j}^{\mathrm{S}}$. Hence, $p_{i}^{\mathrm{C}} \in\left(p_{i}^{\mathrm{S}}, p_{i}^{\mathrm{L}}\right) .{ }^{16}$

If $i$ waits until the second period, with probability $q_{j}$, it captures the follower position. With probability $\left(1-q_{j}\right)$, however, firms quote prices simultaneously in period two. Therefore, $i$ 's expected profit from waiting is,

$$
q_{j} \Pi_{i}\left(R_{i}\left(p_{j}^{\mathrm{C}}\right), p_{j}^{\mathrm{C}}\right)+\left(1-q_{j}\right) \Pi_{i}^{\mathrm{S}}
$$

Firm $i$ 's expected profit from quoting $R_{i}\left(p_{j}^{\mathrm{C}}\right)$ in period one is,

$$
q_{j} \Pi_{i}\left(R_{i}\left(p_{j}^{\mathrm{C}}\right), p_{j}^{\mathrm{C}}\right)+\left(1-q_{j}\right) \Pi_{i}\left(R_{i}\left(p_{j}^{\mathrm{C}}\right), R_{j}\left(R_{i}\left(p_{j}^{\mathrm{C}}\right)\right)\right)
$$

$R_{j}\left(p_{i}^{\mathrm{C}}\right)>p_{j}^{\mathrm{S}}$ since $p_{i}^{\mathrm{C}}>p_{i}^{\mathrm{S}}, p_{j}^{\mathrm{S}}=R_{j}\left(p_{i}^{\mathrm{S}}\right)$ and $R_{j}(\cdot)$ is upward sloping. $R_{j}\left(p_{i}^{\mathrm{C}}\right) \leq p_{j}^{\mathrm{F}}$ since $p_{j}^{\mathrm{F}}=$ $R_{j}\left(p_{i}^{\mathrm{L}}\right)$ and $p_{i}^{\mathrm{C}} \leq p_{i}^{\mathrm{L}}$. Therefore, $R_{j}\left(p_{i}^{\mathrm{C}}\right)<p_{j}^{\mathrm{L}}$ since $p_{j}^{\mathrm{F}}<p_{j}^{\mathrm{L}}$. Since the profit function is increasing in the rival's price and $\Pi_{j}\left(p_{j}, R_{i}\left(p_{j}\right)\right)$ is concave in $p_{j}, \Pi_{j}\left(p_{j}, R_{i}\left(p_{\mathrm{i}}\right)\right)$

\footnotetext{
16 This was suggested in Hamilton and Slutsky (1990).
} 
increases monotonically in the range $\left[p_{j}^{\mathrm{S}}, p_{j}^{\mathrm{L}}\right)$. Since $R_{j}(p) \in\left(p_{j}^{\mathrm{S}}, p_{j}^{\mathrm{L}}\right), \Pi_{j}\left(R_{j}\left(p_{i}^{\mathrm{C}}\right), R_{i}\left(R_{j}\left(p_{i}^{\mathrm{C}}\right)\right)\right)>$ $\Pi_{j}\left(p_{j}^{\mathrm{S}}, p_{i}^{\mathrm{S}}\right)$. Thus Eq. (6)>Eq. (5), and firm i would always strictly prefer committing to waiting, since it can avoid any chance of the low simultaneous profit in period two by committing to the price $R_{i}\left(p_{j}^{\mathrm{C}}\right)$ in period one.

\section{References}

Amir, R., 1995. Endogenous timing in two-player games: a counterexample. Games and Economic Behavior 9, $234-237$.

Amir, R., Grilo, I., 1999. Stackelberg versus cournot competition. Games and Economic Behavior 26, 1-21.

Boyer, M., Moreaux, M., 1987. Being a leader or follower: reflections on the distributions of roles in duopoly. International Journal of Industrial Organization 5, 175-192.

Deneckere, R., Kovenock, D., 1992. Price leadership. The Review of Economic Studies 59, 143-162.

Deneckere, R., Kovenock, D., Lee, R., 1992. A model of price leadership based on consumer loyalty. The Journal of Industrial Economics 40, 147-156.

Dowrick, S., 1986. Von Stackelberg and Cournot Duopoly: choosing roles. Rand Journal of Economics 17/2, $251-260$.

Eckard, E., 1982. Firm market share, price flexibility, and imperfect information. Economic Inquiry 20, $388-392$.

Gal-Or, E., 1985. First mover and second mover advantages. International Economic Review 26/3, 649-653.

Gertler, M., Gilchrist, S., 1994. Monetary policy, business cycles and the behavior of small manufacturing firms. Quarterly Journal of Economics 109, 309-340.

Hamilton, H., Slutsky, S., 1990. Endogenous timing in Duopoly games: Stackelberg or Cournot equilibria. Games and Economic Behavior 2, 29-46.

Henkel, J., 1999. Partial commitments: the value of 'perhaps.' Mimeo, Ludwig-Maximilians University.

Holthausen, D.M., 1979. Kinky demand, risk aversion, and price leadership. International Economic Review 20, $341-348$.

Markham, J.W., 1951. The nature and significance of price leadership. American Economic Review 41, $891-905$.

Martinelli, C., 1997. Small firms, borrowing constraints, and reputation. Journal of Economic Behavior and Organization 33, 91-105.

Nicholls, W., 1951. Price Policies in the Cigarette Industry. Vanderbilt Univ. Press, Nashville.

Ono, Y., 1982. Price leadership: a theoretical analysis. Economica 49, 11-20.

Robson, A., 1990. Duopoly with endogenous strategic timing: Stackelberg regained. International Economic Review 31/2, 263-274.

Rotemberg, J.J., Saloner, G., 1990. Collusive price leadership. The Journal of Industrial Economics 39, $93-111$.

Scherer, F.M., Ross, D., 1990. Industrial Market Structure and Economic Performance. Houghton Mifflin, Boston.

Simon, L.K., Stinchcombe, M.B., 1989. Extensive form games in continuous time: pure strategies. Econometrica 57, $1171-1214$.

Stigler, G., 1947. The Kinky oligopoly demand curve and rigid prices. The Journal of Political Economy 55, $432-449$

Van Damme, E., Hurkens, S., 1998. Endogenous price leadership. Center Discussion Paper.

Von Stackelberg, H., 1952. The Theory of the Market Economy translated by Alan T. Peacock. Chapel River Press, Andover, Hants. 